\title{
The role of organizational culture in policy mobilities - the case of South Korean climate change adlaptation policies
}

\author{
Susann Schäfer \\ Friedrich Schiller University Jena, Institute of Geography, Löbdergraben 32, 07743 Jena, Germany \\ Correspondence to: Susann Schäfer (susann.schaefer@uni-jena.de)
}

Received: 23 April 2016 - Revised: 14 June 2017 - Accepted: 23 June 2017 - Published: 31 July 2017

\begin{abstract}
The conceptualization of policies as mobile and mutable knowledge is the key feature of the recent debate on policy mobilities. Policy mobility studies have focused on the movement and translation of policies as well as on the impact of mobile policies on policy-making processes and governed spaces. Given that policy mobilities have mainly been examined in comparable institutional contexts, the current debate has neglected the role of organizational culture in the translation of policies. Organizational culture is understood as a set of shared assumptions that guide what happens in organizations by defining appropriate practices of policy making. The case study, South Korean adaptation policy, illustrates that organizational culture has a significant impact on the translation of mobile adaptation policy. Besides the claim to consider organizational culture more prominently in the field of policy mobility studies, this paper illustrates the translation process of adaptation policy in the South Korean political system. The practices in South Korean political institutions dealing with climate change adaptation are highly characterized by the avoidance of risks. The propensity to avoid risks leads policy makers to focus on technical solutions to climate change adaptation and to neglect the participation of civil society.
\end{abstract}

\section{Introduction}

The conceptualization of policies as mobile and mutable knowledge is the key feature of the recent policy mobility debate (Cresswell, 2010; Benson and Jordan, 2011; Peck, 2011; Cochrane and Ward, 2012; Temenos and McCann, 2013), a debate which has been strongly influenced by the mobility turn in human geography and other social sciences (Sheller and Urry, 2006; Cresswell, 2006). Empirical studies of policy mobility studies have focused, on the one hand, on the movement and translation of policies and, on the other hand, on the impact of mobile policies on policy-making processes and governed spaces (Peck and Theodore, 2010a; McCann, 2011; McCann and Ward, 2013). The translation of policies and the impact of mobile policies have shown that even similar mobile policies (or policy models) unfold different specifications depending on their embeddedness in local economic, social, and institutional environments (Peck and Theodore, 2010b; Cresswell, 2012). These specifications are rooted in the fact that policy translation processes are collaborative processes with the involvement of policy makers (Czarniawska, 2002) affiliated with political institutions (Jenkins, 2017). Given that mobile policies travel across national borders, the translations of policies take place in diverse political systems which are characterized by different organizational cultures understood as the set of shared assumptions that guide what happens in organizations by defining appropriate practices of policy making (Ravasi and Schultz, 2006). Organizational culture, a central concept in management studies, is used to understand an organization's values and the behavior of actors within organizations assuming that they develop a particular modus operandi over a certain period of time (Hofstede et al., 1990). In order to receive a differentiated picture of organizational culture and its relevance for policy mobility, this paper uses the theoretical perspective of social practices defined as "nexuses of doings and sayings" (Schatzki, 1996) to understand how policy makers deal with and influence the mobility of policies. Since these practices are persistent and define the daily work sequences of policy making (Johnson, 1988; Ravasi and Schultz, 2006), 
they likely have an impact on the translation of mobile policies that are often transformed into "fast policies" due to the quick circulation of policies (Peck and Theodore, 2015). These practices include the formulation of policy documents, the development of measures and tools, and the negotiation with cooperating political institutions. Organizational culture, however, has not been addressed in the ongoing policy mobility debate, even in those studies that examine the translation of mobile policies in those institutional contexts that differ from political institutions or policy communities that shaped and circulated mobile policies (Peck and Theodore, 2010b; Söderström et al., 2013; Machold, 2015; Zapata and Zapata Campos, 2015; Albrecht, 2016).

To fill this gap, this paper evaluates the role of organizational culture in the translation of climate change adaptation policy in South Korea. The focus of the study is the Korean Adaptation Center of Climate Change, founded in 2009, and other political institutions in South Korea dealing with the translation of adaptation policy. The policy makers at the adaptation center drafted the national adaptation master plan in 2010 and were responsible of the implementation of adaptation strategies on the local level. In order to "follow adaptation policy" in the South Korean political system, the author focused on policies in the agricultural sector and on the cooperation of the adaptation center with policy makers from the regional government of one of the nine South Korean provinces (Gangwon Province).

The paper develops the argument to consider organizational culture in policy mobility studies, especially in those cases that seek to examine the translation of mobile policies in national or regional policy settings. When an ethnographic approach is applied to organizational culture, the results provide a nuanced picture of how policies are translated and give insight into the mechanisms of daily policy making. Besides this argument, this paper delivers an interesting insight into the characterization of adaptation policy in South Korea: policy makers show a predisposition to avoid risks; this attitude has led to the prevalence of technical solutions to climate change adaptation and the neglect of participation of regional policy actors and civil actors.

These results provide valuable insight regarding how countries handle the formulation and implementation of adaptation policies, which is a highly relevant topic of climate change research in the social sciences (Burton et al., 2006; Adger et al., 2009; Leary et al., 2009; Dow et al., 2013). Recent studies elaborate on "successful" case studies and manuals for adaptation (Ford and Berrang-Ford, 2011; Moser und Boykoff, 2013; Prutsch and Grothmann, 2014) focusing on governance structures and processes. The debate has, however ignored - except for Weisser et al. (2014) and Eguavoen et al. (2015) in the African policy context - the fact that adaptation is a traveling, mobile policy and that localized policy making needs to take the relational, often transnational context of policy transfer and local translation into account to understand the possibilities and limits of adaptation policy. This study not only contributes to the debate on policy mobilities but also highlights the mechanisms of policy making within and between political institutions - insight that allows a better understanding of the outcomes of adaptation policy in political systems structured similar to South Korea.

After outlining the specifics of the South Korean case study (Sect. 2) and the methodological approach to organizational culture (Sect. 3), the paper presents the practices of translation (Sect. 4) and discusses these in the light of organizational culture and their spatialities (Sect. 5).

\section{Adaptation policy in South Korea - specifics of the case study}

Like many other countries in the word, South Korea has faced climate change impacts in the recent past and is likely to be affected by more severe impacts in the future (Ministry of Environment and National Institute of Environmental Research, 2010). The projections of climate change impacts have led to a stronger consideration of mitigation and adaptation policies in the national policy of South Korea since 2009 (Presidential Committee on Green Growth, 2009a, b). Although South Korea did not sign the Kyoto Protocol due to its low rate of emitted greenhouse gases in the beginning of the 1990s, the country belongs now to the group of emerging economies with a high level of emissions (UNFCCC, 1992). Therefore, South Korea, like most countries in the Global North and those who have experienced significant fossil-based economic growth in the past 2 decades, aims to mitigate greenhouse gas emissions and to adapt to climate change (IPCC, 2014:5). In the case of both mitigation and adaptation, policy models and best-practice blueprints circulate globally, powered by international climate conferences (e.g., UN Conferences of the Parties) and global institutions (e.g., UN Environmental Programme). Whether and how these policy models and blueprints are translated in local policy settings depend on the government's will to address these issues and on the political system. In South Korea, former president Lee Myung-Bak decided to put mitigation and adaptation on the national agenda in 2008 (Presidential Committee on Green Growth, 2009a, b). In a 5-year development plan (Government of Korea, 2010a), the government defined the goals of adaptation policy and the legal framework; the central government and its affiliated bodies carry out adaptation policy. This is a typical outline for the political system in South Korea: the president decides the political agenda, and the central governmental institutions located in the capital, Seoul, formulate and implement policies - a political system structured top-down, with hardly any civil participation (e.g., civil interests groups, environmental non-governmental organizations (NGOs)) or involvement of local governmental institutions (Cummings, 2005). 
Besides the hierarchical political system, which has allowed for the effective but oftentimes also contested implementation of policies, the South Korean government has the strong ambition to disseminate its policy models to other countries (Aboubcar, 2013; Doucette and Riel Müller, 2016), mostly in Southeast Asia, and - in the case of climate and energy policy - to be "a green nation copied by the world" (Government of Korea, 2010b). This ambition is not something new. Rooted in the success of the South Korean political leadership to raise the economic level of the country from being a low-income economy to the fourth-largest economy in Asia, the South Korean government believes that this unique success story is a model that developing economies can copy. The case of climate change adaptation is slightly different but shows similarities in the rationality of the government. From the very beginning, policy makers expressed the goal that the South Korean way should be disseminated to other policy contexts. However, it was new in this case that South Korea had to "import" and implement adaptation policy before it could circulate its version further. In order to understand this import and export, the circulation of policies, this papers not only takes a look at policy documents but also focuses on practices of policy makers within South Korean institutions. This research perspective sheds lights on the micro-processes of policy circulation and underlines that organizational culture plays a significant role in the way how policies are circulated and translated.

\section{A methodological approach to organizational culture}

For the examination of organizational culture, this study adopted an ethnographic approach for the practices within the adaptation center and conducted qualitative interviews with those policy makers from political institutions outside the center who were involved in adaptation policy. Practices and organizational culture are linked in two ways: on the one hand, practices are influenced by organizational culture; on the other hand, practices constitute organizational culture, and through alteration of practices these cultures are changeable. In the policy mobility literature, the translation of mobile policies has been mainly examined with the help of qualitative methods (Peck and Theodore, 2012; Wood, 2016), such as interviews and document analysis (Freeman, 2012; Temenos and McCann, 2012; Müller, 2014). Although these methods are valuable for the investigation of organizational culture, only the ethnography of a political institution can fully deliver the set of constituting translation practices (Marcus, 1995), simply because practices are often habitual and can be overseen in interview situations. This argument has been discussed in the recent theoretical debate on social practices, in which researchers have argued that practices should be studied while they are carried out (Schatzki, 1996; Bongaerts, 2007).
For this paper, the researcher conducted an ethnography of the Policy Division Unit of the Korean Adaptation Center of Climate Change for a period of 4 months in 2010. She was allowed to be present daily in the large office space where all policy makers of this unit had their workplace. The observations and the informal conversations of each workday were documented in a research journal. The participant observation included not only the daily presence at the center but also participation at meetings and conferences, where the researcher accompanied policy makers from the adaptation center. Since the network of political institutions involved in the formulation of the adaptation master plan extended beyond the time available for the investigation, the researcher concentrated the research regarding the translation between political institutions on one sector and spatially on one province. The reason for in-depth consideration of agriculture was that this economic branch was expected to be affected by climate change more than other economic sectors (Korean Rural Economic Institute, 2010; Kim et al., 2010). Despite the specifications of adaptation strategies, the organizational culture between the adaptation center and the political institution dealing with adaptation in agriculture, the Rural Development Administration (RDA), was representative for the political system. Regarding the implementation of adaptation policy, the spatial focus of the ethnography was the implementation of adaptation strategies with policy makers of the regional government in Gangwon Province, one of the nine provinces located in the North East of South Korea. The involvement of policy makers from Gangwon was rooted in the - unlike the other provinces - early interest in the implementation of adaptation policies (Government of Gangwon, 2010). Besides the ethnography in the adaptation center, the researcher conducted 10 expert interviews with those policy makers involved in adaptation policy in the agricultural sector. These policy makers worked in the Rural Development Administration, the Ministry of Environment, and the Agricultural Technology Center.

The notes from the ethnography and the transcripts of the interviews were analyzed using the software Atlas.ti. Social practices that were constitutive to the translation of adaptation policy in South Korea were inductively developed from these qualitative data: adopting foreign "bits and pieces" (Peck and Theodore, 2010a) of adaptation policy (Sect. 4.1), developing domestic adaptation strategies and structures for implementation (Sect. 4.2), and advertising practices of the South Korean adaptation policy to emerging countries (Sect. 4.3). After these practices are outlined in the following chapter, they will be discussed comprehensively in Sect. 5 . 


\section{The translation practices of climate change adaptation policy}

\subsection{Adopting "bits and pieces" of adaptation policy}

The practices of adopting "bits and pieces" of adaptation policy focuses on the duplication of available digital political statements and information as well as the transfer of foreign policy models through the official visits to the places where they were implemented.

The duplication of digital political statements, policies, and even figures was a common practice for the policy makers at the center in the process of compiling domestic policy documents and presentations. In 2010, policy makers in the policy unit of the adaptation center were responsible for developing the content and the introduction of the national adaptation master plan. The introduction, which was first written in English and later translated into Korean, was peppered with statements and quotations from sources such as the EU White Paper for Environment and Climate Change (European Union, 2010), the English Wikipedia text on climate change, the WWF publication "Impacts and Adaptation" (WWF, 2010), the IPCC report, and digital texts from the NGO "People and Place" and the Clean Air Partnership website - albeit without naming their sources (ethnographic field notes, August 2010). In some cases, the South Korean policy makers revised the statements or quotations by adding Korean specifics, for example on local climate change impacts, or deleted words to fit the South Korean context. One of the adjustments was to dramatize climate change and to stress the need for adaptation in South Korea. The policy makers drew on new statistics by the Ministry of Environment that the Korean Peninsula will be "more affected by climate change than the global average" (personal communication with policy maker, May 2010). This dramatization of climate change combined with the implicitly resonating need for adaptation policy was communicated to the Korean public. One of the digitally copied statements was that "climate change adaptation is a must, not an option", a message that eventually appeared on the English brochure of the adaptation center and in a Korean video, available on the center's Web page, to inform the public about climate change adaptation. The speaker used a Korean motto which translates as, "Adaptation to climate change is not a choice; it is a national survival issue" (ethnographic field notes, September 2010).

Besides the duplication of textual statements, policy makers made use of figures, such as the development of the average global temperature or the iconic picture of a polar bear sitting on a small floating ice sheet (presentation of policy maker, October 2010). In several presentations, the division leader of the policy unit had copied this picture into his PowerPoint presentation. During presentations, he commented that without adaptation "people will suffer like this polar bear" (Fig. 1) (ethnographic field notes, October 2010).

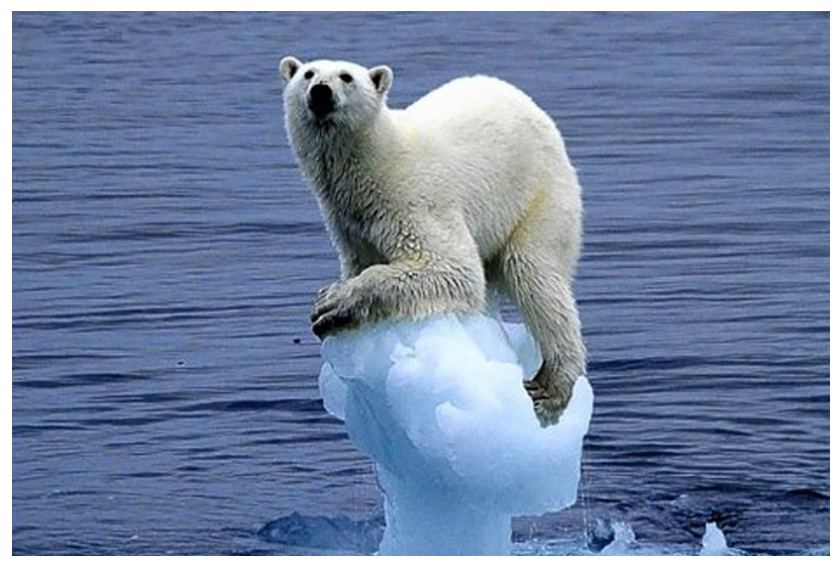

Figure 1. Mobile figure of adaptation policy: the polar bear (@Carla Lombardo Ehrlich).

Whereas policy makers at the adaptation center duplicated digital text statements and figures to justify the foundation of the center and domestic adaptation policy, they actively sought after foreign policy models to adopt them in the South Korean system.

The transfer of foreign policy models was mainly realized through official visits of policy makers of the adaptation center to countries or regions they perceived as models in climate policy, such as Germany or Australia. Often these official trips were motivated by difficulties policy makers faced or by the concern to learn from best-practice projects (personal communication with policy maker, August 2010). In 2009 and 2010, only political institutions close to the Ministry of Environment dealt with adaptation policy, whereas regional governments and civil groups were completely left out at the start of adaptation policy. Therefore, a major point of uncertainty was how to include regional and local policy makers in the implementation of adaptation strategies, especially in those sectors with a regional focus in their implementation: ecosystems, forest, agriculture, marine/fisheries, water management, health, disaster control, and social infrastructure. The initial plan of the adaptation center was to write and provide a "manual for local governments" to implement climate change adaptation plans of the adaptation center (presentation by a policy maker for trip to New Zealand and Australia, August 2010). In order to learn from policy models that successfully included regional policy actors and citizens, a policy maker from the policy division traveled to Melbourne, Australia, as well as Christ Church and Wellington, New Zealand, where adaptation policy was operated bottom-up (Ministry of Environment, 2014) and regional policy makers were actively shaping adaptation processes. During the trip, the policy makers visited different implementation sites and raised the following questions: "What should we include in the manual for local governments?" and "Would it be enough to develop a manual?" (personal communication with policy maker, August 2010). The transfer of the local Australian 
and New Zealand policy models consisted of the opinion that regional policy makers should be considered in the implementation and that a simple manual for adaptation without any dialogue would not lead to the desired implementation of adaptation policy.

A concrete realization of this new conviction was that the policy makers at the adaptation center organized a meeting with participation of the Ministry of Environment, the regional government of Gangwon Province (one of the nine provinces in South Korea), and the adaptation center. The goal of this meeting in August 2010 was to inform regional policy makers and to initiate cooperation with them. In 2010, Gangwon Province was the only regional government contacted by the center. Due to expected regional climate change impacts, the regional government was pushing towards climate change adaptation (ethnographic field notes, September 2010). Other regional governments were not considering climate change adaptation at that time.

The following section will continue to follow the translation process that began with the duplication of political statements and the transfer of policy models. The focus will be on the formulation of adaptation strategies in agriculture and the cooperation between the adaptation center and regional policy makers from Gangwon Province.

\subsection{Developing domestic adaptation strategies and governance structures for implementation}

While policy makers at the adaptation center coordinated the compilation of adaptation strategies, the detailed elaboration of adaptation strategies was assigned to policy makers specialized in the respective sectors. For the agricultural sector, a policy expert from the Rural Development Administration formulated the following strategies: development of assessment tools for climate change monitoring (such as databases or forecast instruments), new cultivation techniques and crop species, measures against livestock diseases, and new irrigation systems. The development of new techniques and tools was undertaken by employees at the Rural Development Administration. The follow-up plan was to teach these new techniques and tools to farmers at agricultural training centers that were spatially dispersed across all South Korean provinces (personal communication with RDA actor, November 2010).

Regarding the formulation of adaptation strategies, there was a consistency between former development strategies and adaptation strategies. In the interview, the policy expert from the Rural Development Administration was critical about climate change adaptation and explained that the adaptation strategies he had submitted to the adaptation center were mainly strategies that existed before the launch of South Korean adaptation policy. The reason, he argued, was that climate change adaptation was a "fuzzy" concept that matched well to the recent agricultural strategies. The only shift between former strategies and adaptation strategies was the strengthening of monitoring tools for climate change impacts (personal communication with RDA actor, November 2010).

The insight that climate change adaptation was not a significant policy concept for the Rural Development Administration has been confirmed in an interview with a policy maker from the Ministry of Agriculture, Food and Rural Affairs, the institution to which the Rural Development Administration officially belongs. The policy maker at the ministry clarified that climate change adaptation did not play any role in the policy making of the Ministry of Agriculture, Food and Rural Affairs. It was foremost a specific policy of the Ministry of Environment, while policy makers in national political institutions used adaptation to climate change rather as a label for existing political strategies (personal communication with policy maker, November 2010).

Whereas the formulation of adaptation strategies belonged to policy makers in national political institutions (ministries or affiliated institutions), the implementation of these strategies was operated by policy makers at the adaptation center. After the official visit to Australia and New Zealand, the adaptation center initiated a meeting with regional policy makers from Gangwon Province. Both policy parties came to the meeting with a similar interest in adaptation policy, but both left with unmet expectations. Whereas policy makers of the adaptation center expected the regional counterparts to willingly implement their adaptation strategies and to support the work of the adaptation center, for example by helping them to compile regional statistics, the policy makers from Gangwon wanted to contribute their expertise regarding adaptation policy, expressed in the regional adaptation plan that was published before the center marked the start of the national adaptation plan. These different expectations collided: in a coffee break during the meeting, an employee of the adaptation center commented that "these (Gangwon plans) are not real adaptation policies" (ethnographic field notes, October 2010). On the other side, regional actors were frustrated that their political suggestions and ideas were not taken seriously. From the beginning of the meeting, the hierarchical inequality between the national and regional policy makers was made perceptible: the location of the meeting, a venue in the capital town, and the seating arrangement during the meeting were chosen for the convenience of the employees of the adaptation center. During the meeting, employees from the adaptation center were sitting in central positions at the table, whereas regional actors had not-so-favorable seats - all in all, they seemed to be the guests during the talk (ethnographic field notes, October 2010).

In an interview with one of the participating regional policy makers from Gangwon Province 6 months after that meeting, he commented on the work of the adaptation center: "The national government has said several times that we should adapt to climate change, but there are things that do not really make sense on the local level. Sometimes we do not understand why we should do that." He added that the national government (the adaptation center) lacks regional 
knowledge: "It seems that they do not know much about the implementation of adaptation" (personal communication with policy maker from Gangwon, March 2011; translated from Korean). The conflict between the adaptation center and the regional government of Gangwon is not surprising given that hierarchical structures were lessened at first sight but that, although the adaptation center was willing to speak with regional policy makers, they did not intend to share their power regarding the definition and formulation of adaptation policy.

\subsection{Advertising South Korean adaptation policy to emerging countries}

Official visits of South Korean policy makers played a major role not only in transferring policy models from foreign places to South Korea but also in disseminating South Korean policies abroad, with the spatial focus to emerging countries in Southeast Asia. These visits were embedded in the adaptation center's goal to establish "national and international climate change adaptation networks" and to assist "government delegations at international discussions on adaptation" (KACCC, 2015). In August 2010, two policy makers participated at the Regional Workshop on Climate Change Adaptation and Mitigation in Phuket, Thailand. The South Korean participants were two among participants from Cambodia, Indonesia, Laos, the Philippines, Thailand, and Vietnam. They traveled to Phuket and held lectures on the development of national adaptation policies with the focus on how to "pass down Korea's technology for adaptation to climate change to nations which are vulnerable to climate change" (Ministry of Environment, 2013). One of the key policies that were disseminated on this and other events was the CCAIS the Climate Change Adaptation Information System, an information delivery system that was in progress in 2010 . The setup of CCAIS reflects the rationality of the South Korean approach to climate change adaptation well. As one policy maker explained at an international event in Seoul, "In order to adapt properly, we need sufficient information" (presentation of policy maker, October 2010). The principle of CCAIS was to collect diverse data - both quantitative and qualitative - and to make them accessible to various actors, foremost to policy makers in different South Korean institutions. The text documents were classified according to publisher/author, form, document size, summary, date, and key words. This was done for qualitative texts, such as South Korean and foreign policy documents, to get fast access to this information "without reading the full paper" (personal communication with policy maker, September 2010). Besides the coordination of adaptation strategies, the setup and maintenance of CCAIS were the major occupations of the adaptation center. The question during this process was not what South Korean policy makers could learn from the data or how non-policy-makers could make use of the data but how to manage the system efficiently. Issues discussed and pre- sented to the foreign audience at workshops, such as the one in Thailand, were related not to the impact of policy transfer but to the functionality of this data storage.

\section{Discussion of translation practices}

The previous sections described translating practices of South Korean policy makers in the domains of policy development, implementation, and dissemination of South Korean policy to foreign policy sites. These practices are rooted in the organizational culture and reflect the specific spatialities of South Korean adaptation policy.

\subsection{Translation and organizational culture}

The duplication of digital political statements, the formulation of the adaptation master plan by multiple authors, and the transfer of foreign policy models - all accomplished within 6 months in 2010 - illustrate the quick and focused launch of adaptation policy in South Korea. The speed of policy making in this case was not exceptional but a common feature of organizational culture in South Korea. In other political studies regarding the introduction of new policies in South Korea (Kim et al., 2013), authors have made similar observations and refer to the short-term and hasty culture with the widely used Korean term "ppalli ppalli" ("fast, fast"), which is applied in business and institutional settings to express this speedy work style. The practices of policy makers at the adaptation center reflect the orientation to present visible results, such as the national adaptation plan, within a short period of time without negotiating a shared definition of climate change adaptation and without discussing who could benefit from the formulated adaptation strategies (to be blinded for review). Two other factors added to the quick and speedy policy style. One factor was the urge to legitimize the center and its activities. The ambitions among the center's leadership were directed not only toward the role in the domestic political system but also toward becoming an international model: one of the "world leading adaptation institutions" (KACCC, 2015). The other factor that fostered the mobility of adaptation policy was the diversity of study backgrounds among the policy makers at the adaptation center and the lack of a joint introduction to climate change adaptation. Given that the South Korean academia had not considered adaptation policy and adaptation as a social process, policy makers who were mainly educated in South Korea lacked knowledge on climate change adaptation. Therefore, knowledge about climate change adaptation and adaptation policy deriving from foreign sources was used by policy makers for the policymaking process.

The ppalli ppalli culture shaped adaptation policy making in South Korean in such a way that it was a quick formulation process with the focus on presentable documents and tools, such as the CCAIS, with hardly no focus on the receivers 
of the formulated adaptation strategies. These practices and the results reflect the focus not only on speed but also on risk aversion, which is a cultural characteristic identified by Hofstede and Bond (1988). In a comparative study, Hofstede and Bond (1988) found that some countries have a strong disposition to avoiding uncertainty, a disposition that shines through the policy making, especially in the case of climate change, where there is - despite climate change projections a significant uncertainty as to how the changing climate will affect economic activities and the well-being of the population. In the study of Hofstede and Bond, South Korea scores highest in the category of risk aversion, which means that the majority of people, although individuals may act differently, value the rigid orientation towards orthodox behavior and the avoidance of unconventional, sometimes innovative approaches. In adaptation policy, the orthodoxy and the disposition to conventional approaches, as an indicator for organizational culture, become evident in the following aspects.

First, the governance of adaptation policy followed the traditional South Korean top-down principle, whereby regional policy makers could not participate in the formulation process and there was no communication with the receivers of national policies regarding their requests and perspectives. This principle is contrary to the supranational agreement of the UNFCCC (1992) and the adaptation policy framework (2005), which is a road map on how to incorporate future climate risk into policy-making processes. The key message of the adaptation policy framework is that "stakeholders are central to the adaptation process" (Conde and Lonsdale, 2007). In other countries, where the mobile policies of climate change adaptation translated into national action frameworks, this aspect of adaptation policy was adopted. For example in Germany, the government initiated a research program with seven model regions to develop best-practice examples of regional adaptation policy and stakeholder participation ("Klimzug" projects) even before the federal government implemented a national adaptation plan (Mahammadzadeh and Chrischilles, 2012; Rotter et al., 2012). Although there is a supranational political agreement on stakeholder participation, the implementation of this mobile policy differs extremely: whereas in Germany the development of adaptation policy started with projects focusing on stakeholder participation, South Korea did not include stakeholders in the formulation process of its adaptation policy.

Second, as a consequence of the lack of stakeholder participation, adaptation strategies in South Korea focused foremost on the development of new tools and measures. The national political institutions could control their developments; it was more reliable in the eyes of policy makers to focus on official tools for adaptation instead of enabling citizens to adapt to climate change in their own ways. Although innovations in tools and measures are required in adaptation processes, a critical aspect in adaptation is the change of behavior (Gifford et al., 2011) of those affected by climatic changes. In the study of Schäfer, it was shown that South Ko- rean farmers were introduced to new tools and measures after they had been developed without their participation. The lack of the farmers' participation resulted in the lack of acceptance given that the first step towards climate change adaptation, making the farmers sensitive to climate changes and impacts, was neglected (Schäfer, 2015).

Third, the focus on monitoring tools, such as CCAIS, underlines that the major challenge policy makers identified was the availability and management of data that could reduce the uncertainty of knowing how climate change will impact diverse economic and social domains in South Korea. Besides the development of new tools and measures, this was one of the major foci of the adaptation center. On the one hand, this focus shows the rationality of the South Korean government to narrow adaptation to a data-driven solution assuming that the analysis of data would suggest one solution. On the other hand, these monitoring tools were instruments that could be easily circulated in foreign policy settings. Given that the South Korean government sought to establish the country as a model in climate politics, policy makers aimed to develop outcomes quickly in order to further circulate them abroad. The rationality of the data-driven solution to climate change adaptation is rooted in the risk aversion that Hofstede and Bond (1988) identified for South Korean society and politics. The further circulation of adaptation policy outcomes is related to the ppalli ppalli principle and the geostrategic aim to exploit adaptation policy as a means by which to gain international reputation. The rationality and the geostrategic aim are entangled with organizational culture in such a way that the practices were shaped by the rationality and were targeted on the geostrategic goal.

\subsection{The spatialities of policy translation}

The translation of adaptation policy in South Korea displays interesting spatialities of policy mobilities that are linked to the geopolitical self-perception of the South Korean government.

For the duplication of digital political statements and the transfer of foreign policy models, policy makers in the adaptation center reached out to political statements and models of the Global North and of environmental NGOs, to those who were known as pioneers in climate policy. They did not transfer policy models of emerging or developing countries, nor of countries that faced similar climate change impacts or had similar socioeconomic structures. Whereas countries of the Global North (including Australia and New Zealand, as well as supranational federations like the EU) were the models for the formulation and implementation in South Korea, the dissemination of CCAIS was directed to emerging countries, foremost to those in ASEAN (Association of Southeast Asian Nations). Simply speaking, adaptation policy was moved from political sites in the Global North to emerging and developing countries by South Korean policy actors who developed their version, or translation, of adaptation policy. 
It is noteworthy that the dissemination of adaptation policy to emerging countries was performed simultaneously to the implementation of adaptation strategies in South Korea. Without having experience in the implementation of precise adaptation strategies, policy makers circulated a model for data management, called CCAIS. This approach allows the conclusion that South Korean policy makers perceived this kind of tool as their international contribution to climate change adaptation. The circulation of CCAIS can be better understood in the context of South Korea's green-policy boosterism (McCann, 2013), a process of green growth policy circulation through the foundation of the Global Green Growth Institute, and of South Korea's successful application to host the UN Green Climate Fund in the South Korean city Songdo (Government of Korea, 2012). The Green Climate Fund is the UN organization that manages the allocation of climate funds between donor and receiving countries (Global Green Growth Institute, 2015). The South Korean government launched the Global Green Growth Institute to assist policy makers abroad in the implementation of green growth policies and invested in the Green Climate Fund to boost its reputation as a pioneer in green and climate politics. In the global discourse on green economy and climate politics, the South Korean government has presented the country as a "bridge between developed and developing countries" (source), a phrase used by the former South Korean president expressing the country's self-perception as a model for developing countries based on the rapid economic success in the second half of the 20th century (Snyder et al., 2015). The idea of the bridge is reflected well in the mobilities of adaptation policy: drawing from Global North policies and disseminating the South Korean version of adaptation to mostly developing countries in Southeast Asia, the policy makers at the adaptation center performed that bridge through their practices - how the South Korean policy was received is yet another question to be answered.

\section{Conclusion}

Based on the empirical study of climate change adaptation policy in South Korea, this paper explored the role of organizational culture for policy mobilities and for the translation of this political agenda. Organizational culture was examined with the help of practices of those policy makers dealing with adaptation policy. Practices and organizational culture are linked in two ways: on the one hand, practices are influenced by organizational culture; on the other hand, practices constitute organizational culture, and through alteration of practices these cultures are changeable.

In this study, practices of policy formulation and development in South Korea were considerably shaped by the ppalli ppalli culture and the disposition to avoid risks, resulting in the state-centered, data-driven translation of climate change adaptation with no participation of those individuals affected by climate change. Besides the view on national adaptation policy, the South Korean government positioned the country as a bridge between countries of the Global North and emerging countries, a political strategy that found expression in the spatialities of South Korean policy mobilities. The goal of the paper was to put organizational culture in perspective for the policy mobility debate, especially in the context of transnational policy mobilities. The benefit of studying organizational culture is to come to a more nuanced understanding of how intersubjective, often unspoken routines, called practices, influence the translation and mobilities of policies.

Data availability. The data are available upon request to the author.

Competing interests. The author declares that she has no conflict of interest.

Acknowledgements. The research presented in this paper was carried out as part of the international research training group TERRECO (GRK 1565/1) funded by the German Research Foundation (DFG) at the University of Bayreuth, Germany, and the Korean Research Foundation at Gangwon National University, Chuncheon, South Korea. The author wishes to thank Detlef Müller-Mahn and Jintae Hwang for providing helpful and constructive comments on earlier versions of this paper, Lea Kvarantan Huber for her feedback, and the anonymous reviewers for their excellent feedback.

Edited by: Myriam Houssay-Holzschuch

Reviewed by: four anonymous referees

\section{References}

Aboubcar, M.: Emerging donors and knowledge sharing for development: the case of Korea, Yonsei J. Int. Stud., 5, 225-238, 2013.

Adger, W. N., Lorenzoni, I., and O'Brien, K. (Eds.): Adapting to climate change: thresholds, values, governance, Cambridge University Press, Cambridge, UK, 2009.

Albrecht, M.: The role of translation loops in policy mutation processes: State designated Bioenergy Regions in Germany, Environ. Plann. C, 0, 1-18, https://doi.org/10.1177/0263774X16669354, 2016.

Benson, D. and Jordan, A.: What have we learned from policy transfer research? Dolowitz and Marsh revisited, Political Studies Review, 9, 366-378, https://doi.org/10.1111/j.14789302.2011.00240.x, 2011.

Bongaerts, G.: Soziale Praxis und Verhalten. Überlegungen zum Practice Turn in Social Theory, Z. Soziol., 36, 246-260, 2007.

Burton, I., Diringer, E., and Smith, J.: Adaptation to climate change: international policy options. Advancing the international effort against climate change, Pew Center on Global Climate Change, 36 pp., Arlington, USA, 2006.

Cochrane, A. and Ward, K.: Guest editorial: researching the geographies of policy mobility: confronting the 
methodological challenges, Environ. Plann. A, 44, 5-12, https://doi.org/10.1068/a44176, 2012.

Conde, C. and Lonsdale, K.: Engaging Stakeholders in the adaptation process, in: Adaptation policy frameworks for climate change: Developing strategies, policies and measures, edited by: Lim, B., Cambridge University Press, Cambridge, 47-66, 2007.

Cresswell, T.: On the Move: Mobility in the Modern Western World, Routledge, New York, 2006.

Cresswell, T.: Towards a politics of mobility, Environ. Plann. A, 28, 17-31, https://doi.org/10.1068/d11407, 2010.

Cresswell, T.: Mobilities II: Still, Prog. Hum. Geog., 36, 645-653, https://doi.org/10.1177/0309132511423349, 2012.

Cummings, B.: Korea's Place in the Sun - A modern history, Norton, New York, 2005.

Czarniawska, B.: A tale of three cities. Or the globalization of city management, Oxford University Press, Oxford, 2002.

Doucette, J. and Riel Müller, A.: Exporting the Saemaul spirit: South Korea's Knowledge Sharing Program and the "rendering technical" of Korean development, Geoforum, 75, 29-39, 2016.

Dow, K., Berkhout, F., Preston, B., Klein, R., Midgley, G., and Shaw, R.: Limits to adaptation, Nature Climate Change 3, 305307, https://doi.org/10.1038/nclimate1847, 2013.

Eguavoen, I., Schulz, K., de Wit, S., Weisser, F., and Müller-Mahn, D.: Political dimensions of climate change adaptation. Conceptual reflections and African examples, in: Handbook of Climate Change Adaptation, edited by: Filho, W. L., Springer, Berlin, Heidelberg, 1183-1199, 2015.

European Union: White Paper. Adapting to climate change - Towards a European framework for action, $\operatorname{COM}(2009)$ 147/4, Brussels, available at: http://ec.europa.eu/health/ph_ threats/climate/docs/com_2009_147_en.pdf (last access: $10 \mathrm{Au}-$ gust 2010), 2010.

Ford, J. and Berrang-Ford, L.: Climate change adaptation in developed nations: from theory to practice, Advances in Global Change Research, Springer Science + Business Media, Berlin, Germany, 2011.

Freeman, R.: Reverb: policy making in wave form, Environ Plann A, 44, 13-20, https://doi.org/10.1068/a44177, 2012.

Gifford, R., Kormos, C., and McIntyre, A.: Behavioral dimensions of climate change: drivers, responses, barriers, and interventions, WIREs Climate Change, 2, 801-827, 2011.

Global Green Growth Institute: available at: http://gggi.org/ about-gggi/background/organizational-overview/, last access: 12 January 2015.

Government of Gangwon: Gangwon's climate change adaptation master plan, Chuncheon, Gangwon Provincial Office, 270 pp., 2010.

Government of Korea: Framework on Low Carbon, Green Growth, Act No. 9931, 2010a.

Government of Korea: Advertisement in The Korea Herald, 2010b.

Government of Korea: Korea invites GCF - Expression of Interest to host the Green Climate Fund, 2012.

Hofstede, G. and Bond, M. H.: The Confucius connection: From cultural roots to economic growth, Organ. Dyn., 16, 4-21, 1988.

Hofstede, G., Neuijen, B., Ohayv, D., and Sanders, G.: Measuring organizational cultures - a qualitative and quantitative study across 20 cases, Admin. Sci. Quart., 35, 286-316, 1990.

IPCC (Intergovernmental Panel for Climate Change): Climate Change 2014 Synthesis Report -Summary for Policymakers, available at: http://www.ipcc.ch/pdf/assessment-report/ar5/wg2/ ar5_wgII_spm_en.pdf, last access: 3 March 2014.

Jenkins, M.: Knowledge and practice mobilities in the process of policy-making: The case of UK national well-being statistics, Polit. Geogr., 56, 24-33, 2017.

Johnson, G.: Rethinking Incrementalism, Strateg. Manage. J., 9, 75-91, https://doi.org/10.1002/smj.4250090107, 1988.

KACCC (Korean Adaptation Center for Climate Change): About us, available at: http://ccas.kei.re.kr/english/menu_5_1.do, last access: 5 July 2013.

Kim, C., Lee, S., Jeong, H., Jang, J., Kim, Y., and Lee C.: Impacts of climate change on Korean agriculture and its counterstrategies, KREI, R593, 305 pp., 2010.

Kim, C.-H., Amaeshi, K., Harris, S., and Suh, C.-J.: CSR and the national institutional context: The case of South Korea, J. Bus. Res., 66, 2581-2591, 2013.

Korean Rural Economic Institute: Agriculture in Korea, Seoul, 515 pp., available at: http://www.krei.re.kr/portlet-repositories/ agri/files/1448584031908.pdf (last access: 10 August 2010), 2010.

Leary, N., Adejuwon, J., Barros, V., Burton, I., Kulkarni, J., and Lasco, R.: Climate change and adaptation, Earthscan, London, UK, 2009.

Machold, R.: Mobility and the Model: Policy Mobility and the Becoming of Israeli Homeland Security Dominance, Environ. Plann. A, 47, 816-832, https://doi.org/10.1068/a140010p, 2015.

Mahammadzadeh, M. and Chrischilles, E.: Klimaanpassung als Herausforderung für die Regional- und Stadtplanung (Adaptation to climate change as a challenge for regional and urban planning), Cologne Institute for Economic Research, Cologne, 2012.

Marcus, G.: Ethnography in/of world system: the emergence of multi-sited ethnography, Annu. Rev. Anthropol., 24, 95-117, https://doi.org/10.1146/annurev.an.24.100195.000523, 1995.

McCann, E.: Urban policy mobilities and global circuits of knowledge: toward a research agenda, Ann. Assoc. Am. Geogr., 101, 107-130, https://doi.org/10.1080/00045608.2010.520219, 2011.

McCann, E.: Policy boosterism, policy mobilities, and the extrospective city, Urban Geogr., 34, 5-29, 2013.

McCann, E. and Ward, K.: A multi-disciplinary approach to policy transfer research: geographies, assemblages, mobilities and mutations, Policy Studies, 34, 2-18, https://doi.org/10.1080/01442872.2012.748563, 2013.

Ministry of Environment: available at: http://eng.me.go.kr/board. do?method=view \&docSeq=8732\&bbsCode=new_news, last access: 15 January 2013.

Ministry of Environment: New Zealand's framework for adapting to climate change, available at: https: //www.mfe.govt.nz/sites/default/files/media/ClimateChange/ nz-framework-for-adapting-to-climate-change-pdf.pdf, last access: 11 November 2014.

Ministry of Environment and National Institute of Environmental Research: Korean Climate Change Assessment Report 2010, Technical Summary, Government Publication Number: 111480523-000649-01, 2010.

Moser, S. and Boykoff, M. (Eds.): Successful adaptation to climate change: linking science and policy in a rapidly changing world, Routledge, London, UK, 2013. 
Müller, M.: (Im-)Mobile policies: why sustainability went wrong in the 2014 Olympics in Sochi, Eur. Urban Reg. Stud., 22, 191-209, https://doi.org/10.1177/0969776414523801, 2014.

Peck, J.: Geographies of policy: from transfer-diffusion to mobility-mutation, Prog. Hum. Geog., 35, 773-797, https://doi.org/10.1177/0309132510394010, 2011.

Peck, J. and Theodore, N.: Mobilizing policy: models, methods, and mutations, Geoforum, 41, 169-174, https://doi.org/10.1016/j.geoforum.2010.01.002, 2010a.

Peck, J. and Theodore, N.: Recombinant workfare, across the Americas: transnationalizing fast welfare policy, Geoforum, 41, 195208, https://doi.org/10.1016/j.geoforum.2010.01.001, $2010 \mathrm{~b}$.

Peck, J. and Theodore, N.: Follow the policy: a distended case approach, Environ. Plann. A, 44, 21-30, https://doi.org/10.1068/a140085p, 2012.

Peck, J. and Theodore, N.: Fast policy: Experimental Statecraft at the Thresholds of Neoliberalism, University of Minnesota Press, Minnesota, 2015.

Presidential Committee on Green Growth: Road to our future: Green Growth - National strategy and five-year plan (20092013), 25 pp., 2009a.

Presidential Committee on Green Growth: Green Growth Korea, available at: www.greengrowth.go.kr (last access: 24 January 2009), 34 pp., 2009 b.

Prutsch, A. and Grothmann, T. (Eds.): Climate Change Adaptation Manual: Lessons learned from European and other industrialised countries, Routledge, London, UK, 2014.

Ravasi, D. and Schultz, M.: Responding to organizational identity threats: Exploring the role of organizational culture, Acad. Manage. J., 49, 433-458, https://doi.org/10.5465/amj.2006.21794663, 2006.

Rotter, M., Hoffmann, E., Hirschfeld, J., Schröder, A., Mohaupt, F., and Schäfer, L.: Stakeholder participation in adaptation to climate change - Lessons and experiences from Germany, Federal Environment Agency (Umweltbundesamt), Dessau-Roßlau, 2012.

Schäfer, S.: Climate Change Adaptation in South Korea - Environmental Politics in the Agricultural Sector, Transcript, Bielefeld, 2015.
Schatzki, T.: Social practices: a Wittgensteinian approach to human activity and the social. Cambridge University Press, Cambridge, 1996.

Sheller, M. and Urry, J.: The new mobilities paradigm, Environ. Plann. A, 38, 207-226, https://doi.org/10.1068/a37268, 2006.

Snyder, S., Bradford, C., Dalton, T., Howe, B., Kosch O'Donnell, J., and O'Neil, A.: Middle-Power Korea: Contributions to the Global Agenda, Council on Foreign Relations Press, New York, 2015.

Söderström, O., Randeria, S., Ruedin, D., D’Amato, G., and Panese, F. (Eds.): Critical mobilities, EPFL Press, Lausanne, 2013.

Temenos, C. and McCann, E.: The local politics of policy mobility: learning, persuasion, and the production of a municipal sustainability fix, Environ. Plann. A, 44, 1389-1406, https://doi.org/10.1068/a44314, 2012.

Temenos, C. and McCann, E.: Geographies of policy mobilities, Geography Compass, 7, 344-357, https://doi.org/10.1111/gec3.12063, 2013.

UNFCCC: GHG emission profiles for non-Annex I Parties, available at: http://unfccc.int/files/ghg_data/ghg_data_unfccc/ ghg_profiles/application/pdf/kor_ghg_profile.pdf (last access: 24 November 2016), 1992.

Weisser, F., Bollig, M., Doevenspeck, M., and Müller-Mahn, D.: Translating the "adaptation to climate change" paradigm - the politics of a travelling idea in Africa, Geogr. J., 180, 111-119, https://doi.org/10.1111/geoj.12037, 2014.

Wood, A.: Tracing policy movements: methods for studying learning and policy circulation, Environ. Plann. A, 48, 391-406, https://doi.org/10.1177/0308518X15605329, 2016.

WWF (World Wildlife Fund): Impacts and adaptation, available at: www.worldwildlife.org/climate/impactsandadaptation.html, last access: 13 December 2010.

Zapata, P. and Zapata Campos, M.: Unexpected translations in urban policy mobility. The case of the Acahualinca development programme in Managua, Nicaragua, Habitat Int., 46, 271-276, 2015. 